\title{
Chapter 16 \\ Segregation in London: A City of Choices or Structures?
}

\author{
David Manley
}

\begin{abstract}
This chapter provides a comprehensive overview of the socio-economic segregation in London. The cosmopolitan nature of the city means there is an interwoven complexity that prevents the separation of social, cultural and economic residential trajectories of the population. As a result, the chapter explores socio-economic segregation within the context of the changing nature of the (sub)urban contexts. In particular, the chapter documents not only the occupational segregation but also introduces the often-used dimension of ethnicity and pairs it with the less commonly explored age and tenure dimensions through which the social structure of the city is inscribed. This enables a broader understanding of the rapid changes that have been wrought on the micro-scale can be understood in the context of a city that has, in terms of the overall composition, changed little.
\end{abstract}

Keywords Segregation $\cdot$ London $\cdot$ Housing $\cdot$ Ethnicity $\cdot$ Occupation

\subsection{Introduction}

Originally founded by the Romans as Londinium, the city has prospered over almost two millennia growing from its initial roots as a trading port on the River Thames to national capital and international finance hub. In terms of global reach, London is on par with New York (GaWC 2020). Over this period, the functions of the city, the relative population composition and the social, economic and ethnic population distributions have changed, but London remains a city of contrasts. With almost 9 million people living in the Urban Core, it is the most populous of any European Capital, a population that grows substantially when including the wider commuter belt areas of over 14 million people (Eurostat 2018). It is also one of the most important cities globally in terms of finance, business and industry as well as a major tourist destination on the international stage, and exerts considerable influence nationally as the seat of Government for the United Kingdom. As one of the original Global

D. Manley ( $\square)$

University of Bristol, Bristol, UK

e-mail: D.Manley@bristol.ac.uk 


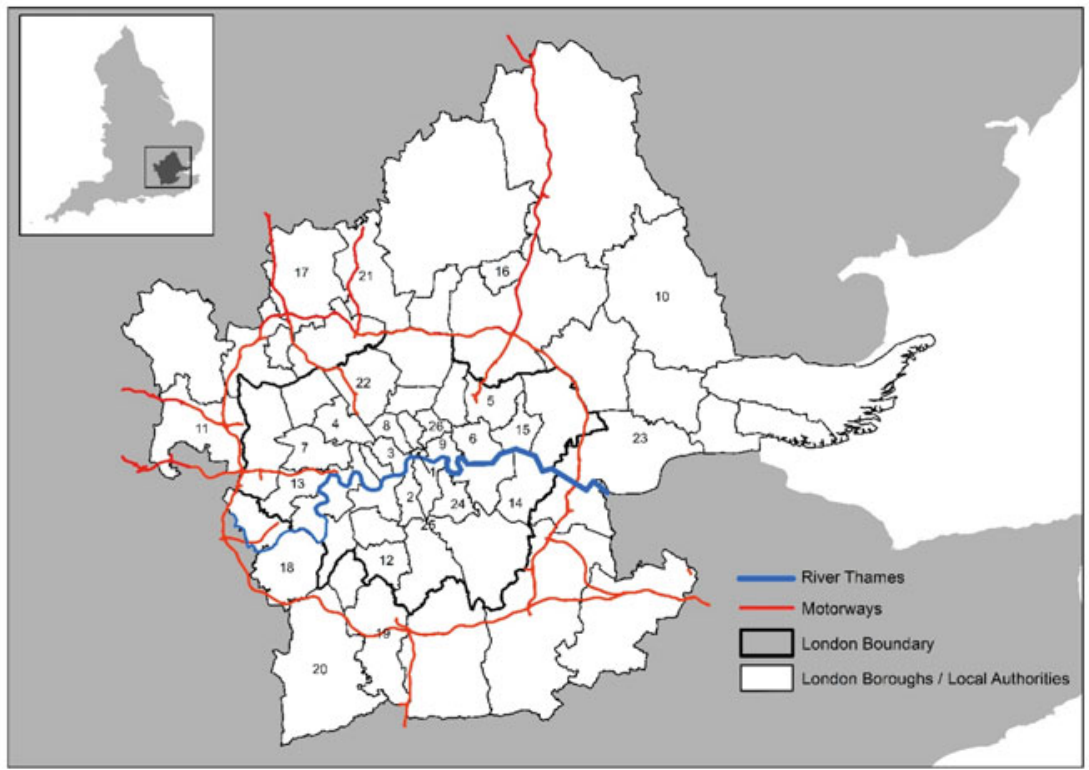

1 City of London; 2 Lambeth; 3 Kensington and Chelsea; 4 Brent; 5 Redbridge; 6 Newham; 7 Ealing; 8 Camden; 9 Tower Hamlets; 10 Chelmsford; 11 South Buckinghamshire; 12 Sutton; 13 Hounslow; 14 Bexley; 15 Barking and Dagenham; 16 Harlow; 17 St Albans; 18 Elmbridge; 19 Reigate and Banstead; 20 Mole Valley; 21 Welwyn; 22 Barnet; 23 Thurrock 24 Lewisham; 25 Southwark; 26 Hackney. (Note only those Boroughs and Local Authorities referred to in the chapter text are identified)

Fig. 16.1 The Boroughs of London and surrounding Local Authorities that make up the OECD area

Cities (Sassen 1991) it is set apart from the rest of the UK on almost all measures: it has greater ethnic diversity, greater cultural breadth, multiple but interlinked and highly varied housing markets, and with 32 Boroughs it represents multiple cities within a city. This chapter presents an overview of multiple dimensions of segregation in London, starting by focusing on the occupational groups and then exploring the socio-economic composition of the population within the wider The Organisation for Economic Co-operation and Development (OECD) region. This region extends far beyond the 32 Boroughs traditionally considered to be 'London' administratively or culturally to crucially include the metropolitan hinterland (see Fig. 16.1 for a mapped description).

\subsubsection{Ethnicity}

The diversity of the population in London has been built over many waves of internal migration and international immigration. In terms of international immigration, until 
the end of the Second World War, entry into the UK was largely dominated by residents from countries in what became the Commonwealth. After the British Nationality Act in 1948, the right to enter and work in the UK was granted to over 800 million residents in the former countries included in the British Empire. The resulting flows were, of course, much smaller than this, but there was still a substantial number of economically motivated migrants entering the UK, and especially London, to take up positions in occupations with a deficit of labour supply-such as transportation and the newly formed national health service. Within the Boroughs of London, the experience of migration has been highly varied. For instance, Lambeth and Kensington and Chelsea were Boroughs where the Black Caribbean population first settled in the city, and Brixton is still regarded as the Caribbean Capital of Britain. Other Boroughs such as Hackney, Brent, Lewisham and Southwark also played important roles in the initial years for these groups. By contrast, people belonging to the Bangladeshi communities in London have tended to concentrate in the Borough of Tower Hamlets. Within the vast diversity of groups, the other two largest are the Pakistani (around Redbridge and Newham) and the Indians (Ealing and Brent). There is, then, there is the potential for substantial ethnic segregation at the macro (Borough) scale.

\subsubsection{Economic}

Economically, the residential history of London is just as varied as it is for ethnicity. Meen and colleagues (2012) highlighted the potential for the social and economic profile of neighbourhoods to steadfastly remain static within the wider urban system, even in the presence of some substantial (e.g. regeneration or gentrification) shocks in the longer term. London's social mosaic was initially mapped out by Booth (1903) using street by street observation to give classifications across the whole of the city. It is notable in his classification that areas such as the present-day Kensington and Chelsea were already identified as belonging to the 'upper-middle and upper classes, wealthy' group, just as any modern-day classification would conclude. Similarly, the neighbourhoods in the Belsize Park ${ }^{1}$ area (Camden) were similarly identified and continue today to be areas of wealth and affluence. By contrast, neighbourhoods located in the Borough of Tower Hamlets, especially those located in was known as 'Stepney' were classified in the 'lowest class', 'very poor' and 'poor', neighbourhoods. Tellingly, these correspond closely with those neighbourhoods identified as being the poorest in London using modern deprivation measures such as the Index of Multiple Deprivation (Smith et al. 2015). Although these are only a couple of brief exemplars, they allude to the wider trend which despite London being a seat of substantial gentrification (from the initial work by Ruth Glass (1964) to the more recent Super Gentrification literature of Bulter and Lees 2006; Butler et al. 2013) the structure of many neighbourhoods within London has been locked into the long term

\footnotetext{
${ }^{1}$ The name Bellsize is derived from the French 'bel assis' which translates into English as 'well situated'.
} 
reproduction of spatial inequality. Investigating the change in spatial characteristics of occupation and focusing particularly on the places of residence of the working class and middle-class, Manley and Johnston (2014) revealed that substantial change was a rare phenomenon over a relatively long (10 year) period.

\subsubsection{Housing}

In recent years London has attracted substantial investment from globally wealthy investors and has become an international site of investment for the superrich major housing developments, especially in interventions in the central areas (see Atkinson 2016). This process has fuelled the continuation of much longer-term trends within the city where the residential infrastructure of the city is often highly sought after. Many current property developments are targeted at the private market, often for owner occupation or private rent. Where mixed tenure has been explored, the implementations have been sometimes controversial (see the development of gated play spaces, Guardian 2019a) or highly exclusionary, such as the poor door ${ }^{2}$ access to mixed tenure developments (see for instance Osborne 2014).

However, the British housing system was not always like this. The UK is traditionally viewed as a Liberal Welfare State with early moves into state provision in the first part of the 1900s under the Liberal Government of Asquith. This state provision of housing was substantially bolstered in the post-war period (1942 onwards) with the introduction of the National Health Service. In terms of the development of the city, the welfare state was critical in the organisation, access to and redevelopment of slum areas across the UK. In particular, London was the setting for many of the early 'council houses' (herein referred to as social housing) under the instruction of the Estates Department of the then London County Council (LCC). The creation over much of the 1900s of large estates across the city provided the backdrop for a largely mixed population at the city scale where all Boroughs provided some form of social housing. Since inception, it has been possible for tenants to purchase the property they rent from the council provider, but until the late 1970s, it was rare for tenants to exercise their Right to buy (RTB). However, in 1980 the Housing Act passed by the then Conservative government of Margret Thatcher formalised the policy and in the decades that followed, over 4 million properties were sold across the UK, leading to a substantial reduction in the availability of rental stock. Within London, where to date, almost of 290,000 properties have been sold (DCLG 2019), the consequences of RTB played out differentially in each borough. In some parts of the city, former social housing stock is in private ownership and worth well over $£ 1$ million while equivalent houses elsewhere are still valued at a 10th of that price. Regardless

\footnotetext{
${ }^{2}$ The term 'poor door' refers to the practice of putting separate entrances on multi-dwelling developments so that those residents in the cheaper (often denoted as affordable or rented) properties are distanced from residents in the more expensive apartments by literally entering the building through different entrances.
} 
of location, the RTB was a major element in the residualisation of social housing, resulting in a reduced stock available to a smaller section of society. It was then also a process that leads to social housing being increasingly viewed as a tenue of last resort. The ultimate expression of this residualisation was seen in the early hours of 14 June 2017 when the Grenfell Tower caught fire, and 72 lives were lost in the ensuing blaze. Grenfell Tower, owned by Kensington and Chelsea London Borough Council with the Kensington and Chelsea Tenant Management Organisation acting as Landlord disaster, highlights the complexity of the two-tier housing system that the RTB reinforced. Those tenants living in the apartments which remained owned by the council would be managed as traditional social housing tenants with inspections and the ultimate housing responsibility falling to the local authority, or the representatives they appointed. By contrast, those flats bought under RTB but existing in the same tower block would not be under scrutiny to the same degree. While the leaseholder remains the same, the RTB either as a dwelling for the owners or as a private market rental, the upkeep and maintenance is a private issue.

\subsubsection{Chapter Outline}

In the sections that follow, an in-depth assessment of segregation by occupation is presented using multiple measures. This is followed by a discussion about segregation focusing on the characteristics of the city explored above-ethnicity, and housing type-along with age as a further important demographic characteristic. Data are drawn from the 2001 and 2011 UK Census, the largest source of data for the UK population. UK Census data is not available at an individual level, so in order to explore segregation, it is necessary to use aggregated areal units: in this chapter, the Lower Super Output Area (LSOA) is used, representing 'neighbourhoods' which have on average around 1400 people. By considering multiple characteristics, we can explore the extent of different types of segregation in the metropolitan area and develop a wider understanding of the social geography of the city.

\subsection{Inequality and Occupational Segregation}

The Gini Index for the United Kingdom since 1961 demonstrates a clear increase in inequality. In 1961 the UK had a Gini coefficient of 0.25, which increased slightly through the 1970s and 1980s. After 1980 the Gini increased to 0.35 by 1991 increasing again in the middle of the 2000s to about 0.36 . By 2011 the figure had begun to fall and there is evidence, post-2008, that the trend is in decline; however, whilst this might be regarded positively and suggest a decline in inequality, the reduction should be interpreted with the Global Financial Crisis in mind. Gini reduction can occur through a number of processes that result in the gap between the richest and poorest declining. It might be that the real incomes of the poorest increase, thus 
providing those most in need with greater financial security. However, it could also be that the movement is the result of the richest seeing a decline in their incomes and wealth while the poorest do not see any material gain in their circumstances. In the moments after the financial crisis, there is evidence that it was the latter of these processes that drove the decline, not the former, evidence supported by the slight but clear increases in the Index value in recent years as the UK has left the recession of the 2008 crisis behind. Looking forward towards a post-Covid-19 city, it is likely that there will be substantial changes in the Gini coefficient again far beyond that of the 2008 recession.

The Gini is a useful measure of inequality, but it only tells a small part of the wider story and the details within the measure matter, as does the geography of wealth distribution. In the UK, wealth is concentrated in the Southern part of the country, with much of the financial activity around London. Moreover, even with a stable or declining headline figure, the differences between the richest and poorest are stark: the income of highest earners is estimated to be 6.8 times that of the lowest earners while the overall wealth of the richest members of British society is estimated at 316 times that of the poorest (according to ONS Wealth and Assets Survey July 2014 to June 2016). It is, then, against this backdrop of declining macro inequality but with an expectation of a more complex micro picture that we explore the OECD London area in more depth.

Figure 16.2 decomposes the population into occupational categories into three groups as Top Middle and Bottom (Fig. 16.2a) or using the nine categories from the NS-SEC (Fig. 16.2b). The overall trend in the wider London OECD region has been one of professionalization. Although the Bottom group has not declined (recording $14 \%$ in both periods), the Top group has grown, increasing from 32 to $38 \%$. Using the more detailed NS-SEC groups, it is clear that this growth has occurred in the Professional group at the expense of the Managerial class, which has shrunk slightly, as well as decreasing the size of the Middle group. The composition of the NS-SEC groups which make up the Middle group are largely similar in size over the 10-year period, the notable exception being the Administrative class, which has declined by a third, and which accounts for the majority of the Middle decline.

a)

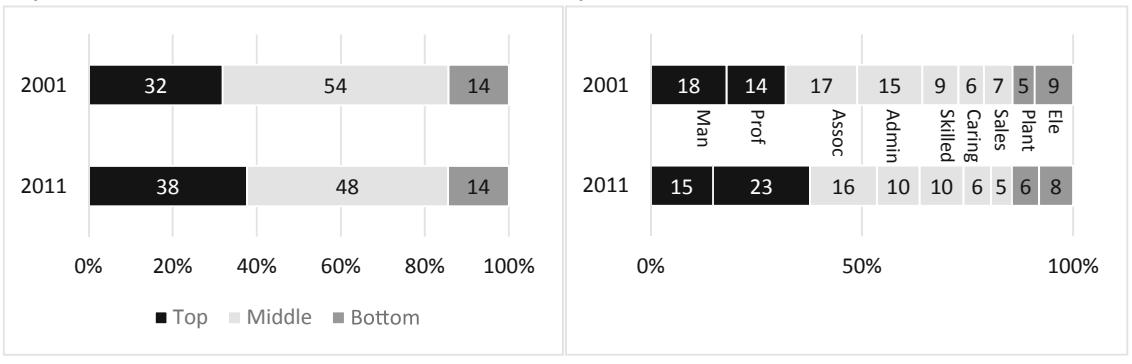

Fig. 16.2 Occupational structure of London 2001 and 2011 for the a top middle and bottom, and b NS-SEC groups 
Table 16.1 Index of dissimilarity (multiplied by 100) for occupational groups in OECD London, 2001 (lower part of the table) and 2011 (upper part of the chart). Bold denotes the greater ID pair value, italics indicate identical ID value

\begin{tabular}{|c|c|c|c|c|c|c|c|c|c|c|c|c|}
\hline & MAN & PRO & APR & ADM & SKI & SER & SAL & MAC & ELE & TOP & MID & BOT \\
\hline MAN & & 15 & 14 & 23 & 30 & 32 & 33 & 38 & 40 & & & \\
\hline PRO & 13 & & 10 & 22 & 32 & 29 & 30 & 38 & 37 & & & \\
\hline APR & 12 & 12 & & 20 & 30 & 28 & 29 & 37 & 36 & & & \\
\hline ADM & 19 & 24 & 18 & & 17 & 18 & 18 & 22 & 25 & & & \\
\hline SKI & 28 & 34 & 28 & 15 & & 20 & 20 & 15 & 23 & & & \\
\hline SER & 23 & 28 & 21 & 13 & 15 & & 15 & 21 & 16 & & & \\
\hline SAL & 26 & 31 & 24 & 13 & 14 & 13 & & 20 & 16 & & & \\
\hline MAC & 34 & 40 & 33 & 21 & 14 & 19 & 16 & & 20 & & & \\
\hline ELE & 32 & 36 & 29 & 20 & 17 & 15 & 14 & 14 & & & & \\
\hline TOP & & & & & & & & & & & 18 & 36 \\
\hline MID & & & & & & & & & & 18 & & 20 \\
\hline Вот & & & & & & & & & & 34 & 18 & \\
\hline
\end{tabular}

MAN Managers; PRO Professionals; APR Associate professionals; ADM Administrative Jobs; SKI Skilled workers; SER Service; SAL Sales; MAC Plant Machine Workers; ELE Elementary Workers

Of course, the occupational composition charts do not consider the neighbourhood distribution of the occupational groups. To address this, the index of dissimilarity (Table 16.1) is used to reveal some clear occupational segregation patterns. Whilst the overall conclusion is that segregation has increased ${ }^{3}$ between 2001 and 2011, this is not the case for all occupational pairs. For example, comparing the Professional category against the Associated Professionals, those in Administrative Jobs, the Skilled Jobs group, the Sales workers and the Machine Workers segregation has declined. However, these represent the exceptions to the general increase. The greatest increases in occupational segregation are observed between groups at either end of the table, for example, between the Managerial group and both the Sales and Elementary occupations. Focusing on the disaggregated occupational groups in the table, it is clear that the increases all involve either the Managerial, Service or the Elementary groups suggesting that there is a distinct trend for those in the lowest (Elementary) or the highest group (the Managers) to increasingly live apart from the other occupational groups in residential space. The other group noted, Service workers, is one that is very diverse in composition with some members being similar in characteristics to the higher groups and others to members of the lower groups. As such, this is not an unreasonable, or unexpected, conclusion to reach in the context of the changes in the residential structure of neighbourhoods an idea we revisit later on: the changes in housing provision and the increasing house prices in central city areas lead us to conclude that the Manager's segregation is likely the result of a process

\footnotetext{
${ }^{3}$ Note, increase refers only to a numerical change in the value of the index and is therefore being used descriptively rather than denoting a process of change as revealed by a statistical significance test, see Manley et al. (2019) for more discussion.
} 
of residential choices being expressed in their home locations, while for those in Elementary occupations is more likely to be the result of being residualised housing or neighbourhoods that are less attractive to those with greater spending power or forced out of the areas they previously lived in as a result of gentrification processes. In the right-hand part of Table 16.1, ID values for the aggregated groups are presented. They confirm that the greatest segregation is between the Top and Bottom groups in both time periods, and that there has been an increase in segregation between 2001 and 2011. The segregation between the Bottom and Middle group, and Middle and Top is largely static over time. This supports the idea of greater spatial inequality.

\subsection{Location Quotient Maps}

The location quotient maps report the concentration for the Top Group (Fig. 16.3) and the Bottom Group (Fig. 16.4). For the Top Group the LQ measure reports expansion and a spreading out of the distribution across the city. Kensington and Chelsea are the key concentration areas of the Top groups in the central city in both 2001 and 2011, as is the far northern reach of the OECD metropolitan area. On the eastern side, there is a smaller pocket of concentration in the Chelmsford area (referencing area 10 on Fig. 16.1), which disappears during the decade between the Censuses (the transformation is from the highest category in 2001 to the lightest in 2011). By contrast, there is a relative lack of individuals in the Top group running along the central area, which maps on the Thames and as then moves eastwards, through more traditionally working-class areas. In terms of the expansion, there are clearly areas which have seen either an increase in concentration or now represent concentrations of workers in the Top group. This is especially true for the northern reaches of the OECD area, but there is also evidence of the same outcome in the south. Without a decrease in the Top group elsewhere, this suggests an increase in the absolute number of workers in these occupational positions. Using these trends, it is reasonable to conclude that over
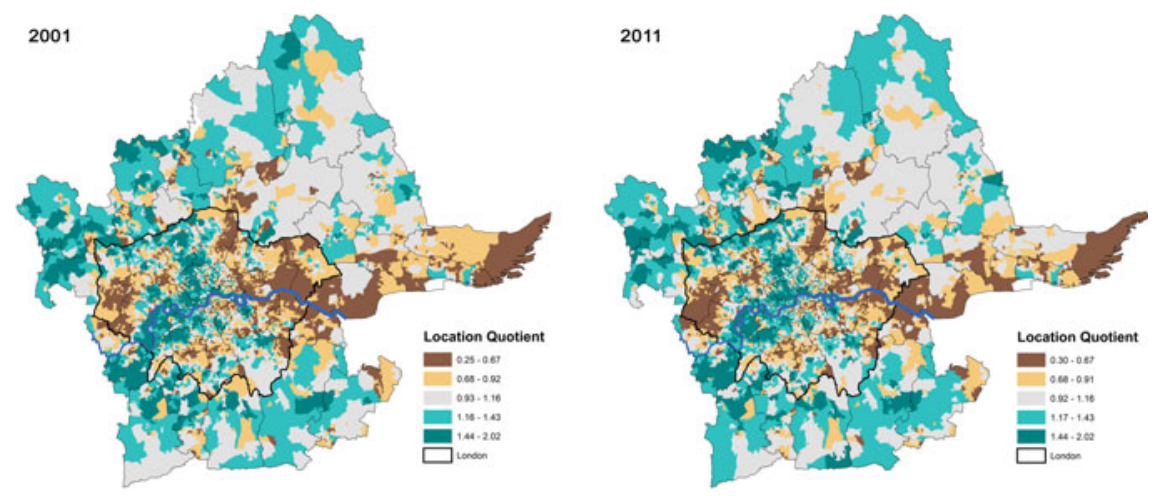

Fig. 16.3 Location quotient maps of the 'top' occupation groups 

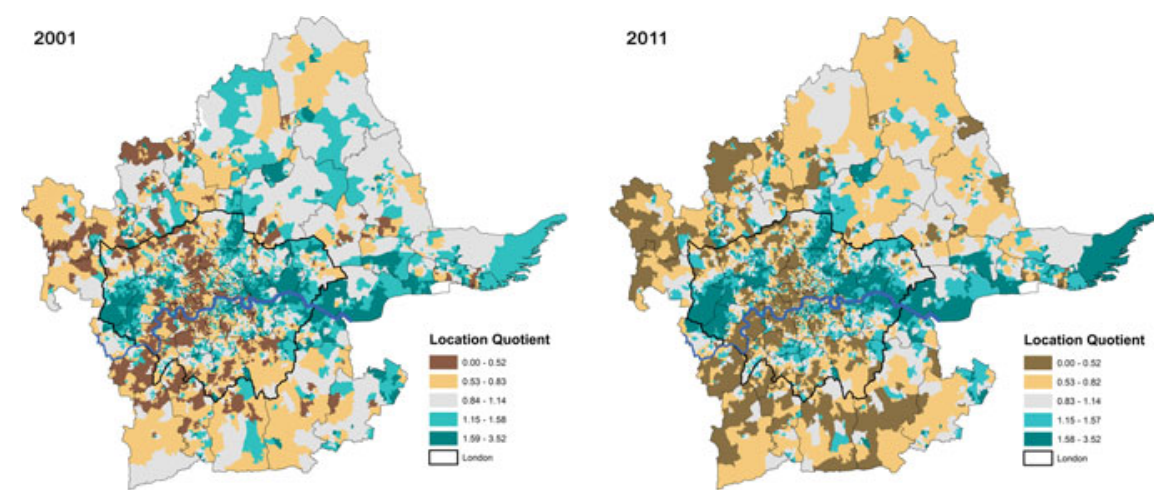

Fig. 16.4 Location quotient maps of the 'bottom' occupation groups

the 10-year period, more people have entered these neighbourhoods in top positions, expanding the Top group.

In Fig. 16.4, the LQ of the bottom group is reported. The separation of occupational groups is clear when these maps are compared to the previous set. To the western side of London, the concentration is to the north of the professional cluster, focusing on Spelthorne, Hillingdon and Hounslow, and on the far eastern side in Bexley and Barking and Dagenham. Between 2001 and 2011, there was little overall change in the occupational structure of the workforce in London, but there was a substantial increase in size of around 30\% (see Manley and Johnston 2014). However, the way that the expansion in population has played out in the residential housing market has not been consistent between groups. Whereas the professional occupations have experienced a spreading out, occupying new neighbourhoods across the city, the people in bottom occupations have remained spatially constrained. In fact, rather than spreading their growth has been through intensification in those areas where they were already concentrated. Together these changes hint at a polarisation at the bottom end. The final point to note for the bottom group is the cluster in the northeast of the city focused strongly on Harlow. Here there is a strong and persistent cluster in both time periods, which is spatially distinct to the borough and exhibits a sharp decline as soon as you move beyond the immediate boundaries of Harlow.

\subsection{Maps of Typologies}

For the typology, as with other chapters, each major group (Top, Middle and, Bottom) were split into four categories (using the share of each group as: $0-29 \%$; 30-49\%; $50-59 \%$, or; over $60 \%$ ). For this chapter, neighbourhoods, where one group represented over $60 \%$ are identified as being dominated by that group. The Polarized neighbourhoods are those where any of the groups fall between 50 and $59 \%$ and 
Table 16.2 Summary of the neighbourhood typology in Fig. 16.5

\begin{tabular}{l|l|l}
\hline & $2001 \%$ & $2011 \%$ \\
\hline Polarized top & 6.4 & $\mathbf{1 4 . 1}$ \\
\hline Polarized middle & 67.6 & 45.6 \\
\hline Polarized bottom & - & 0.1 \\
\hline Mixed & 14.5 & $\mathbf{3 5 . 0}$ \\
\hline Middle dominate & 11.3 & 1.0 \\
\hline Top dominate & 0.3 & $\mathbf{4 . 2}$ \\
\hline Total number of LSOAs & 6643 & 6729 \\
\hline
\end{tabular}

the Mixed neighbourhoods are those with the combinations of the two lower categories for all three groups (in other words, there is no dominant group or polarisation occurring). Not all potential combinations of neighbourhood types and groupings are realised in the maps, although all are, theoretically, possible. A summary of group membership is provided in Table 16.2.


Fig. 16.5 The typologies for LSOAs in the London OECD area in a 2001 and b 2011 along with the concentration of the top socio-economic group in London during c 2001 and d 2011 
In 2001 the Polarised Bottom Group did not exist, yet by 2011 it has appeared. However, the creation of a new group is not as substantial a change is it appears at first, because of all the LSOAs in London the Polarized Bottom (that is, a neighbourhood where the occupational groups of Manufacturing and Elementary dominate) applies only to a single neighbourhood located in Ealing (see back to Fig. 16.1). Thus, whilst the addition of a new grouping is, in reality, a relatively small change, the increase in Polarized Top neighbourhoods is not (growing from $6.4 \%$ of LSOAs to $14.1 \%$, see Table 16.2). This is partially a reinforcing of the polarized top areas that were already present in Kensington and Chelsea in filling large parts of the North to North West of the City extending as far as the Local Authorities of St Albans and Chiltern (in the county of South Buckinghamshire). Where more areas are Polarized for the top group, an equivalent increase has occurred in the Top Dominates group such (from 0.3 to $4.2 \%$ ). Many of the areas classified into this group about the Polarized Top areas largely south of the River Thames (including Elmbridge) which is also South of Heathrow Airport) and into the Local Authorities for Reigate and Banstead as well as Mole Valley (both of which are beyond the traditional boundary of London and in the county of Surrey). There are also pockets of Top Dominated neighbourhoods in the north of the Metropolitan area, including the commuter towns in the Chilterns, St Albans, as well as the more traditional London Boroughs of Welwyn and Barnet and the town of Hatfield (in Welwyn). This suggests at least two processes may be at play in the changing structure: for the commuter areas, there may be a movement into these areas either from the more centrally located areas of the City or choosing to locate here as an entry point to the rest of the Metropolitan area.

In terms of the multicultural and multifaceted city, the growth in mixed areas is substantial (from 14.5 to $35 \%$ ). In the north-eastern side of London, running from Thurrock (25) on the Thames Estuary and Chelmsford in Essex (10) to Welwyn (24). In these areas, there are individuals working in occupations that are classified in all three of the groups (Top, Middle and Bottom groups) such that each group is presented. Whereas the mixing was largely a peripheral issue in 2001 with some central areas having no (or very few) mixed areas, it is the case now that, with the exception of the City of London Borough (which is a special case area anyway), there are no Boroughs without mixed areas. Many of the new Mixed areas were previously Polarised Middle areas (and to a much lesser extent Middle Dominated areas), suggesting that members of both the Top and Bottom are moving into areas in place of residents in the Middle_-in other words, neighbourhoods are both upgrading and downgrading.

\subsubsection{Location of the Top Occupational Group}

The concentration of managers and professionals has remained relatively static over the 10-year period between 2001 and 2011. In 2001 and 2011, 20\% of the top group population could be found in $10 \%$ of the neighbourhoods. Figure 16.5c, d demonstrates that the location of the $10 \%$ of places has also stayed static with top 
quintile locations in the north of the OECD region beyond the bounds of the core of London, a clear concentration in the Central part of the city and a few areas in the southern reaches. By contrast, the least concentrated neighbourhoods for the Top group cut a clear slice through the middle area of the map extending from the west to the east, interrupted only by the central concertation. It is also notable that there are no LSOAs without at least a couple of Top residents at both Census points.

\subsection{Contrasting Dimensions of Segregation}

Occupational segregation represents an important dimension by which the divisions of the urban residential space can be explored and there are other equally as important dimensions that can be considered. To develop a more rounded picture of segregation in London, the Index of Dissimilarity is recalculated for ethnicity, age and tenure. Starting with ethnicity, to allow a similar comparison to the occupational groups, the ethnic diversity of the London Metropolitan area was coded into Majority (all White British) and Minority (all other ethnic groups) to provide a binary classification. The message that is apparent here is that there has been a small decline in segregation as measured by the Index of Dissimilarity over the 10-year period (from 0.46 to 0.44). By comparison to the occupational segregation above, both of these figures are higher, suggesting that ethnic segregation is greater than occupational in the wider London area. ${ }^{4}$ This concurs with the literature for the rest of the UK, which in general suggests that there has been a decline in ethnic segregation and whilst the geographical extent of this study is different to the usual definition of London, it is unsurprising that it reflects the wider trend (see Catney 2016) for the UK in general and Harris (2012) for London in particular, although note the use of school pupil data in the latter which necessarily focuses on the younger age groups only, not the Population Census) (Table 16.3).

Of course, the dichotomisation of ethnicity into two categories provides an overview, but it does obscure much of the detail between groups: the minority groups are, as highlighted in the introduction, comprised of many different ethnicities. To provide greater depth, we decompose the majority versus minority comparison into the major ethnic subgroups used across the UK Census. Using these five groups that are largely comparable over time, the picture of segregation for the major ethnic groups is not as clear cut as it was when dichotomised. Nor is it as clear cut as it was for occupation. There has been both increase and decline over the decade; this data reports on, with no clear single message. For instance, the White/Mixed, White/Other and Mixed/Other pairings have higher D values in 2011 than in 2001. By contrast, the White/Asian, Mixed/Asian, Mixed/Black, Asian/Black, Asian/Other and Black/Other have lower values, while the White/Black shows no change. This suggests that overall the trend has been for ethnic deconcentration. Of the increases,

\footnotetext{
${ }^{4}$ Although as above, direct comparisons between ID values and across groups are to be made very cautiously see Manley et al. (2019).
} 
Table 16.3 Index of dissimilarity (multiplied by 100) for major ethnic groups in 2001 (below the diagonal) and 2011 (above the diagonal)

\begin{tabular}{|c|ccccc|cc|}
\hline & WHITE & MIXED & ASIAN & BLACK & OTHER & MAJORITY & MINORITY \\
\hline WHITE & & 22 & 4 & 43 & $\mathbf{3 7}$ & & \\
MIXED & 2 & & 33 & 23 & $\mathbf{2 7}$ & & \\
ASIAN & $\mathbf{4 1}$ & $\mathbf{3 6}$ & & 4 & 32 & & \\
BLACK & 43 & $\mathbf{2 5}$ & $\mathbf{4 3}$ & & 32 & & \\
OTHER & 29 & 26 & $\mathbf{3 7}$ & $\mathbf{3 6}$ & & & \\
\hline MAJORITY & & & & & & & 44 \\
MINORITY & & & & & & 46 & \\
\hline
\end{tabular}

The white category includes the White European, White Irish and White other groups. The Asian includes Indian, Pakistani, Bangladeshi. The Black represents the Black Caribbean and Black African. Other is all other groups in the Census. For the dichotomised comparisons, the majority is only the White British. All other groups fall under the Minority heading

the greatest is in the 'Other' category (from 0.29 to 0.37 ), but caution should be exercised when interpreting this change simply because of the heterogeneous nature of the 'Other' grouping. The other changes in segregation are smaller, all in the second decimal place.

The next dimension of segregation that we present refers to age. Age has recently been the focus of increased attention in the segregation literature (see Sabter et al. 2017). The processes around ethnic and, to a certain extent, occupational are different to age. The previous dimensions, to a certain extent, focus on separation and discrimination as drivers. Within the residential landscape, there are further reasons why people may experience segregation by age. These include the presence of institutions that cater specifically to certain age groups (for the older individuals, these could be care homes, while for younger residents could include university halls of residence) and will therefore imprint segregation into the landscape. Away from the extremes of age, the older someone is, the more likely they are to have resources to purchase more exclusive housing or have already entered more exclusive neighbourhoods before they increased in price. It is worth noting that, also unlike the categories around ethnicity and occupation, which have clear social construction, age is something that all individuals experience over time and regardless of ethnicity, occupation, class or gender. Moreover, the age profile of an area can change without any residential mobility taking place-again, as people age, the group to whom an area is identified against will change and the demographic processes of birth and death further alter the composition. As such, it represents a different type of segregation-one with alternative process-driven causes-but one which is important nevertheless.

In terms of the degree of segregation (Table 16.4), it is worth highlighting that the levels of segregation as measured by the Index of Dissimilarity are lower than they were for ethnicity (Table 16.3) and many of the occupational groups (Table 16.1). Note that we do not group the age categories together into supergroups as was done for occupation or ethnicity because it does not make sense to reduce the detail here. The greatest segregation is between the youngest and oldest groups $(0.26)$ 
Table 16.4 Age segregation for 2001 (below the diagonal) and 2011 (above the diagonal)

\begin{tabular}{|l|cccc|}
\hline & Age 18-24 & Age 25-44 & Age 45-64 & Age 65 Over \\
\hline Age 18-24 & & 15 & 2 & 26 \\
Age 25-44 & 13 & & 17 & 25 \\
Age 45-64 & 2 & 16 & & 12 \\
Age 65 Over & 24 & 21 & 12 & \\
\hline
\end{tabular}

Table 16.5 Tenure segregation for 2001 (below the diagonal) and 2011 (above the diagonal)

\begin{tabular}{|l|cccc|}
\hline & Outright Own & Mortgage Own & Social Renting* & Private Renting \\
\hline Outright Own & & 15 & 55 & 38 \\
Mortgage Own & 15 & & 49 & 35 \\
Social Renting & 55 & $\mathbf{5}$ & & 43 \\
Private Renting & $\mathbf{4 1}$ & $\mathbf{3 8}$ & $\mathbf{4 7}$ & \\
\hline
\end{tabular}

*Social Renting includes both renting from a Housing Association and renting from Council

and the younger middle group (0.25). By contrast, the two middle groups and the youngest and middle groups are less segregated. This reinforces the idea suggested above that both the structures of institutional living - for both age groups - and the finance required to purchase (or rent) property is likely to push the extremes in age apart. However, as noted above as well, the continuous nature of ageing means that the segregation observed here may not be stationary through the life course. Finally, it is important to note that, unlike the previous measures where some groups have observed an increase while others have experienced a decrease in segregation for the age groups, there are no pairs that have experienced a decrease.

The overall message for housing tenure segregation (Table 16.5) is one of little change in terms of the intensity of segregation, which in many senses is not surprising (recall the work of Meen et al. 2012 discussed in the introduction). The development of housing is a long-term investment and so a substantial change in the tenure profile of neighbourhoods is not expected. However, there are, as was highlighted in the introduction, few ways through which tenure can change-for social renting, ${ }^{5}$ it is through the right to buy moving from renting to owning. The change from owned to private renting is a simpler move, as is the reverse.

An issue that has become increasingly important in London, and many other global cities, has been the increase in households that are very wealthy. For the purposes of identifying these groups and to highlight the segregation of the wealthier groups, owner-occupation is sub-divided into owned with a mortgage (the most common

\footnotetext{
${ }^{5}$ In this discussion, we have combined two forms of social renting-renting from the council and renting from Housing Association-because although we acknowledge that they are different tenures the numbers in some of the Boroughs are very small and therefore would be difficult to estimate. Moreover, in the wider societal discourse, the distinction around the origin of the property is not often made and the catch all label social renting applied.
} 
route to house purchase where the money is borrowed from a lender such as a bank or building society) and owned outright which in the context of much of the London market is an expression of high wealth. The segregation between the owning (mortgage) and the owning (outright) and social renting have remained static. There has been a slight fall in segregation between social renting and owning with a mortgage (the right to buy is likely to be an explanation here, with the right to buy tenants accessing their purchase via a mortgage, although some redevelopment and inclusion of mixed tenure developments may also provide an insight). The main feature of interest here, however, is the magnitude of the Index of Dissimilarity. Compared with the other dimensions of segregation we have considered (age, ethnicity and occupation), the pairwise comparison between social renting and other tenure forms are the highest of all the comparisons (up to 0.55). ${ }^{6}$ What this suggests is that segregation in London is very much driven by the location of the housing that a household accesses: housing is built in clusters and those smaller clusters of tenure types often are co-located in broader neighbourhoods with similar housing. Although there has been a push towards creating a greater mixing of tenures (see, for instance, Bridge et al. 2011), the fixity of housing - it takes large financial investments and timespread over substantially large areas of the city to fundamentally alter the urban spatial structure. As a result, the underlying housing stock does not change very much from year to year, or even over a ten-year period, and so the neighbourhoods reproduce themselves. In terms of the changes in segregation, the biggest has been for private renters. Here there has been a decrease for all pairwise combinations. As the period 2001 to 2011 saw an increase in the prevalence of private renting, this is not a surprising outcome.

\subsection{Conclusions}

Segregation is and always has been a complex and multi-faceted issue, and with increasing diversity and concern around the mixing of populations (on many dimensions), it is not an issue that is going to be solved anytime soon. What is clear from this chapter is that there are many dimensions along which segregation can be measured. Some, such as ethnicity, refer to (historical) discriminatory practices and have exclusionary outcomes which have been linked to further societal problems

\footnotetext{
${ }^{6}$ Although tenure is the largest it is important to note that the measures of segregation are not net of each other. Therefore, the tenure segregation outcomes do not take into account the distribution of age, ethnicity or occupational all of which are likely to be conflated with access to and the distribution of individuals in the tenures (see Manley et al.2019) for a discussion about the issue of conflation and net measures of segregation). Regardless of this critique, however, this is an instructive exploration of the multiple dimensions and as housing tenure is the one issue that is considered in this chapter that has a spatial fixity to it-you can only living in social renting housing if there is a socially rented property available in the neighbourhood, with similar restrictions for the private renters and owners as well-it is reasonable to consider that tenure distribution is the greatest determinant of segregation in the city.
} 
and unrest (see Home Office 2001). Other dimensions like occupational segregation whilst still reflecting separation and potential social tensions also represent spatial expressions of wider social inequalities and difference as well as the outcomes of social power expressions: those with higher occupational status and greater wealth are able to access much more of the capital than those in the lower occupational categories. Real housing choice is a luxury and choice requires the ability to pay.

Age segregation, by contrast, presents a different conceptualisation of social processes. Individuals, and their households, require and desire different facilities and amenities over the life course: what works well for people in their early adulthood (18-24) does not necessarily reflect the needs of those in the middle of the traditional family rearing ages (25-44) or those who are moving into the later stages of their working life (45-64) and retirement (65+). Unlike ethnic groupings, and to a lesser extent, the occupational groups, people will experience all the categories through the ageing process. The question, which we cannot address here, then becomes one of whether or not cohorts are segregating and ageing in situ thus reinforcing segregation over time, or are neighbourhoods providing shelter for people at various points through their life course, and people then pick up and move on as they age? There is evidence that the transmissions of wealth between generations may exacerbate intra-generation segregation. It has been reported that up to $25 \%$ of first-time buyers in the UK are accessing property thanks to the bank of Mum and Dad (Guardian $2019 b$ ). Those with housing wealth will be further enabled to choose where to live compared to those without it (see Galster and Wessel 2019). However, although there is some evidence in the literature (see, for instance, Willetts 2010; McKee 2019), this is not a debate that has, yet, been fully explored in the wider literature.

Ultimately, this leaves tenure segregation. Whilst the previous three dimensions all related to characteristics of people, the final dimension refers to a characteristic of the property. As a result, it is a different type of segregation and one which refers to the spatial structure of the city. Some groups are excluded from some tenures: higher earners cannot access social renting. Those with low incomes will not be able to buy outright, or possibly even buy with the mortgage. Often the younger households will be in private renting because they lack the means for a deposit to access owner-occupation. However, we know that different groups within the previous dimensions-often ethnic minority groups, often individuals in lower occupational groups-are overrepresented in some of the tenures. As a result, we propose that the housing structure of the city serves as a key driver of the spatial expression of inequality - segregation - and to reduce this inequality requires long term investment and oversight in terms of planning, the production of housing, and the types of housing and its locations. 


\section{References}

Atkinson R (2016) Limited exposure: social concealment, mobility and engagement with public space by the super-rich in London. Environ Plan A Econ Space 48(7):1302-1317

Booth C (1903) Life and labour of the people in London, vol 1. Macmillan

Bridge G, Lees L, Butler T (eds) (2011) Mixed communities: gentrification by stealth? Policy Press

Butler T, Hamnett C, Ramsden MJ (2013) Gentrification, education and exclusionary displacement in East London. Int J Urban Reg Res 37(2):556-575

Butler T, Lees L (2006) Super-gentrification in Barnsbury, London: globalization and gentrifying global elites at the neighbourhood level. Trans Inst British Geograp 31(4):467-487

Catney G (2016) Exploring a decade of small area ethnic (de-) segregation in England and Wales. Urban Stud 53(8):1691-1709

DCLG (2019) Table 685: annual Right to Buy sales by local authority (final version). https://www. gov.uk/government/statistical-data-sets/live-tables-on-social-housing-sales\#right-to-buy-sales. Site accessed 16 Dec 2019

Eurostat (2018) Metropolitan area populations. Eurostat, 19 July 2018. https://appsso.eurostat.ec. europa.eu/nui/show.do?dataset=met_pjanaggr3\&lang=en. Accessed 7 May 2019

Galster G, Wessel T (2019) Reproduction of social inequality through housing: a three-generational study from Norway. Soc Sci Res 78:119-136

GaWC (2020)GaWC city link classification 2018. https://www.lboro.ac.uk/gawc/world2018link. html. Accessed 19 March 2020

Glass RL (1964) London: aspects of change, vol 3. MacGibbon \& Kee

Guardian (2019a)Why can't they come and play?: housing segregation in London, 26 March 2019. https://www.theguardian.com/society/2019/mar/26/why-cant-they-come-and-playhousing-segregation-in-london. Accessed 22 July 2019

Guardian (2019b) What first home buyers should know about the bank of Mum and Dad. https://www.theguardian.com/australia-news/2019/jul/01/what-first-home-buyers-shouldknow-about-bank-of-mum-and-dad

Harris R (2012) Local indices of segregation with application to social segregation between London's secondary schools, 2003-08/09. Environ Plan A 44(3):669-687

Home Office (2001) Community cohesion: a report of the independent review team (Cantle report)

Manley D, Johnston R (2014) London: a dividing city, 2001-11? City 18(6):633-643

Manley D, Jones K, Johnston R (2019) Multiscale segregation: multilevel modeling of dissimilarity - challenging the stylized fact that segregation is greater the finer the spatial scale. Profess Geograph 1-13. OnlineFirst

McKee K (2019) Generation rent is a myth-housing prospects for millennials are determined by class. The Conversation, 03.01.2019. https://theconversation.com/generation-rent-is-a-myth-hou sing-prospects-for-millennials-are-determined-by-class-108996

Meen G, Nygaard C, Meen J (2012) The causes of long-term neighbourhood change. In: Understanding neighbourhood dynamics. Springer, Dordrecht, pp 43-62

Osborne H (2014) Poor doors: the segregation of London's inner-city flat dwellers'. Guardian 25:2014

Sabater A, Graham E, Finney N (2017) The spatialities of ageing: evidencing increasing spatial polarisation between older and younger adults in England and Wales. Demograph Res 36:731-744

Sassen S (1991) The global city: New York, London, Tokyo. Princeton paperbacks, New York

Smith T, Noble M, Noble S, Wright G, McLennan D, Plunkett E (2015) The English indices of deprivation 2015. Department for Communities and Local Government, London

Willetts D (2010) The Pinch: how the baby boomers took their children's future-and why they should give it back. Atlantic Books Ltd 
Open Access This chapter is licensed under the terms of the Creative Commons Attribution 4.0 International License (http://creativecommons.org/licenses/by/4.0/), which permits use, sharing, adaptation, distribution and reproduction in any medium or format, as long as you give appropriate credit to the original author(s) and the source, provide a link to the Creative Commons license and indicate if changes were made.

The images or other third party material in this chapter are included in the chapter's Creative Commons license, unless indicated otherwise in a credit line to the material. If material is not included in the chapter's Creative Commons license and your intended use is not permitted by statutory regulation or exceeds the permitted use, you will need to obtain permission directly from the copyright holder.

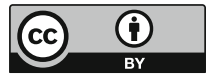

